\title{
Espaço e tempo como dimensões do conhecimento e objeto de ensino-aprendizagem em História
}

space and time as knowledge dimensions and object of teaching-learning in History

Carlos Augusto Lima Ferreira*

Edicarla dos Santos Marques**

\section{Resumo}

O artigo analisa a temática espaço-tempo, fundamental no processo de ensino-aprendizagem de História, e suas implicações no cotidiano da sala de aula. Essa discussão torna-se ainda mais necessária no atual contexto de inserção contínua das Novas Tecnologias da Informação e Comunicação (NTIC) nos ambientes escolares, as quais modificam a prática docente e as formas de apreensão das noções de espaço e tempo. Como as novas espacialidades dos ambientes virtuais, das redes sociais, e as atuais compreensões temporais desencadeadas pelas configurações tecnológicas que emergem do nosso cotidiano têm alterado as percepções dos sujeitos em relação ao conhecimento histórico? Propomos uma reflexão sobre as práticas docentes associadas a essas percepções num momento em que as regras impostas por uma sociedade cada vez mais digital (re) dimensionam o fazer histórico.

Palavras-chave: tempo; espaço; ensino-aprendizagem de História.

\section{Abstract}

In this text, we seek to elaborate on the subject of space-time, fundamental in the process of teaching and learning of history and its implications on daily class. This discussion becomes even more necessary in the current context of continuous insertion of New Information and Communication Technologies (ICTs) into the school environments, which modify the teaching practice and the ways the notions of space and time are apprehended. How have the new spatialities of virtual environments, social networking, and the current understanding of time, triggered by the technological settings that emerge from our daily lives, changed the perceptions of the subjects with regards to historical knowledge? We propose a reflection on the teaching practices associated to such perceptions, especially nowadays, when the rules imposed by an increasingly digital society (re)dimension the making of history. Keywords: time; space; History Teaching-Learning.

\footnotetext{
*Departamento de Educação, Graduação e Mestrado em História, Universidade Estadual de Feira de Santana (UEFS). Av. Transnordestina, Novo Horizonte. 44036-900 Feira de Santana - BA Brasil. caugusto@uefs.br

** Departamento de Educação, Universidade Estadual de Feira de Santana (UEFS), e Rede Pública Estadual de Ensino da Bahia. Av. Transnordestina, Novo Horizonte. 44036-900 Feira de Santana - BA - Brasil. edistoria@yahoo.com.br
} 
A discussão sobre tempo e espaço é um ponto fundamental para o ensino de História e faz parte do nosso cotidiano, contribuindo para a compreensão da realidade vivida e das noções sobre a História. Muitos autores já discutiram essas dimensões numa perspectiva histórica. ${ }^{1}$ Fernand Braudel $^{2}$ discorreu sobre as apreensões temporais em curta, média e longa duração. Já E. P. Thompson ${ }^{3}$ se deteve nos marcadores do tempo e, de algum modo, nas novas formas de concepção temporal e estratégias de controle do tempo/trabalho instauradas pelas sociedades modernas. Sabe-se, sobretudo, que esse é um diálogo profícuo no meio historiográfico. Esse debate, todavia, ainda pouco alcança o espaço das salas de aula.

Nesse sentido, apresentamos a presente discussão numa tentativa de trazer de modo simples um tema relativamente complexo, pelas dimensões abstratas que o perpassam. O nosso objetivo é aproximar essa problemática do lócus da sala de aula, direcionando o presente texto aos professores do ensino básico, levando-os a refletir sobre como os referenciais espaço-temporais, trazidos pelos alunos de suas vivências cotidianas extraescolares, podem dialogar com outros referenciais que os auxiliem na construção de conhecimentos históricos. Para tanto, buscamos analisar, ainda, as formas pelas quais o professor de História pode possibilitar leituras sobre tempo e espaço que se diferenciem das abordagens recorrentes nos livros didáticos (positivistas e/ou marxistas estruturalistas) e mesmo afastar-se das práticas que incorporaram equivocadamente as contribuições da História Nova.

Essa temática torna-se ainda mais importante com o acelerado processo de desenvolvimento das Novas Tecnologias da Informação e da Comunicação (NTIC), o qual desencadeou um novo período histórico da civilização humana: a sociedade da informação. Nesse ínterim, as discussões sobre tempo e espaço, no âmbito escolar, devem estar pautadas também na dimensão tecnológica que assume o cotidiano e nas várias implicações dessa mudança.

Nós, professores de História, consideramos fundamental refletirmos sobre as implicações das questões expostas na nossa prática diária do ensino de História. Temos sabido trabalhar com essas noções imediatas do tempo presente, frequentemente dissociadas, pelos alunos, do conhecimento histórico? Como as novas compreensões espaciais têm participado das nossas aulas? São questões que propomos para autorreflexão sobre o ensino de História. 


\section{AS PRIMEIRAS REFERÊNCIAS SOBRE TEMPO E ESPAÇO}

Quando ingressa na escola, a criança traz uma série de experiências que já lhe permitiram dar início à construção das relações espaciais, além de já possuir uma visão própria do mundo e da sociedade na qual está inserida. A construção da noção de espaço, pela criança, passa por uma série de etapas, algumas das quais acontecem espontaneamente e outras exigem uma sistematização que deve ocorrer nas séries iniciais do ensino fundamental.

Antes mesmo de ser capaz de representar o espaço, a criança já consegue percebê-lo graças ao contato com os objetos, utilizando os sentidos. Ou seja, num primeiro momento, o espaço da criança é um espaço de vivência (ação): compõe-se dos lugares onde mora, passeia e brinca e dos objetos que aí existem e que ela utiliza. A criança percebe o espaço por meio de seu próprio corpo; assim, as relações espaciais desenvolvem-se e tornam-se mais complexas à medida que ela amplia seu espaço de ação. Quando começa a engatinhar, a criança tem a tendência de se agarrar aos móveis, ficar de pé e apanhar objetos cujo acesso era anteriormente dificultado, visto que ela dependia de outras pessoas para se deslocar. À medida que a criança aprende a andar, subir escadas e correr, ela vai ampliando cada vez mais seu espaço de ação. Seu mundo vai 'crescendo' com ela. A escola é um dos primeiros ambientes exteriores à sua casa onde a criança constrói as primeiras percepções sobre o tempo/espaço. María Jesús Comellas Carbó, em seu trabalho sobre as habilidades básicas da aprendizagem, afirma que

podemos defender que una educación vivenciada que utilice sistemáticamente el descubrimiento progresivo de las nociones fundamentales y de sus múltiples combinaciones, que explote todas las posibilidades de expresión simbólica y gráfica para ir hacia el descubrimiento de la abstracción, será un buen camino que lleve al niño hacia una maduración y hacia la adquisición de unos aprendizajes, previniendo posibles dificultades o trastornos que puedan derivarse de una inmadurez o falta de dominio en esta área. ${ }^{4}$

$\mathrm{Na}$ escola, é comum solicitarmos à criança que represente (desenhe) determinado espaço - a sala de aula, por exemplo. Os resultados são registros daquilo que a criança percebeu nesse espaço, e o que ela representa deve ser analisado levando-se em conta as relações que ela estabelece com o meio. 
Muitas vezes as relações sensíveis (emocionais) interferem em sua expressão, tendo como resultado desenhos nos quais se observam exageros e/ou omissão de detalhes. As interações com esse espaço é que possibilitarão o enriquecimento dessa noção, que é elaborada mediante vivências significativas. Porém, essas crianças ainda são pouco estimuladas a pensarem sobre os tempos e/ou espaços na perspectiva dessas balizas como construções humanas; antes disso, são condicionadas a assimilarem as concepções 'corretas'.

Sobre esse aspecto assinalou Tomoko Paganelli:

A escola, ao invés de oferecer às crianças atividades como, por exemplo, exercícios de lateralidade, psicomotores (pular, saltar, correr, rasgar papéis, etc.), conhecimento do seu próprio corpo, que a ajudarão a firmar essas noções, além de as prepararem para elaborar noções projetivas (o espaço perceptivo, percebido) e euclidianas (espaço concebido, representado), nos anos subsequentes, acaba por propor atividades como dar os limites do município, os principais rios, colorir e preencher mapas, que elas ainda não têm maturidade psicogenética para realizar, truncando todo esse processo de construção espaço-temporal. (1987, p.22-27)

$\mathrm{Na}$ Educação Infantil e no Ensino Fundamental I a criança constrói as primeiras noções de tempo e espaço que a auxiliarão no desenvolvimento de uma percepção acerca do conhecimento histórico. Sabemos, sobretudo, que o professor de História, em específico, possibilita que a criança modifique vivências cotidianas sobre tempo e espaço e construa novas noções. Entretanto, essas novas construções poderão estar pautadas em epistemologias de ensino que não levem em consideração os referenciais dos alunos construídos no seu cotidiano. São os professores de História os primeiros responsáveis pela articulação entre os saberes trazidos à escola pelos alunos e os saberes a serem construídos necessários à configuração de uma compreensão sobre o conhecimento histórico.

Entretanto, a prática dos professores de História, principalmente os de $6^{\circ}$ e $7^{\circ}$ anos do ensino fundamental, tem se revelado frágil, no que tange à compreensão do espaço e do tempo de forma histórica. Quanto a este último, é substancial o número de atividades docentes que se tornam simples cronologia acerca da História das civilizações, a linha do tempo, no dizer de Edgar De Decca, o 'varal do tempo'. Como reflexo, os alunos dessas séries demonstram dificuldade para compreender as noções espaço-temporais. Porém, esse 
mesmo 'varal' pode ser ressignificado na prática docente e utilizado de tal modo que outras noções de tempo possam ser compreendidas, como veremos um pouco mais à frente.

Observamos que o ensino de História praticado em escolas da educação básica, via de regra, pouco tem conseguido fazer para que o aluno perceba a relação entre os fenômenos sociais ocorridos no passado e no presente. Isso ocorre em função da postura teórica assumida pelos professores que é, quase sempre, uma postura marcadamente marxista estruturalista - na qual os sujeitos praticamente desaparecem em meio às estruturas - e/ou positivista. A prática de ensino positivista aborda os fatos e o tempo histórico em uma sequência linear, cronológica e estanque, com grandes heróis e alguns fatos relevantes. Para essa corrente, o ensino de História é um fim em si mesmo e serve para "moldear la conciencia colectiva de la sociedad y la conciencia temporal de la ciudadana". ${ }^{5}$

Impor aos jovens uma representação 'correta' no momento em que ele está construindo a noção de tempo e espaço só tende a inibir a própria expressão em relação às categorias. Ao buscar representar o meio, os jovens estão estabelecendo um diálogo com a realidade, e o enriquecimento dessa linguagem se dá de modo processual, desde que eles estejam sempre movidos em seu interesse. É sempre em relação aos sujeitos que vivenciam o tempo e fazem uso dos espaços que eles devem existir. Tomemos nossos alunos como referências. O trabalho com situações vivenciadas e aplicadas à sala de aula contribui para o processo de desenvolvimento mental, o que facilita a construção de novos conceitos, oportunizados pelo professor nos espaços escolares.

Ernesta Zamboni e Sandra Regina Ferreira de Oliveira, por exemplo, analisaram algumas dessas apreensões sobre os aspectos espaço-temporais estruturantes da realidade escolar e perceberam como estes interferem na constituição das competências cognitivas dos alunos ao observarem empiricamente duas salas de $3 \underline{a}$ série do ensino fundamental. As autoras direcionaram o foco investigativo para a organização espacial das salas de aula, bem como para as identidades dos alunos constituídas em relação aos usos dos ambientes escolares. Elas identificaram que:

A apropriação do espaço físico é importante para os alunos das séries iniciais do Ensino Fundamental, porque possibilita, dentre outras coisas, a exposição de tra- 
balhos realizados, a partir dos quais a professora pode estabelecer relações entre diferentes assuntos que são abordados no decorrer do ano. O espaço físico da sala de aula também pode ser utilizado para expor os acordos coletivos realizados em sala de aula e com os quais todos têm compromisso. Desta forma, as paredes de uma sala de aula podem, ou não, ser uma espécie de memória da turma. ${ }^{6}$

No que diz respeito ao tempo, as autoras focalizaram as atividades desenvolvidas em sala de aula relacionadas aos aspectos de "sequência, ordenação, simultaneidade, linha do tempo, calendário, cronologia, passado, presente e futuro" (Zamboni; Oliveira, 2009, p.123). Também identificaram que as atividades não incluíam antecipação do que seria feito, e quando uma combinação prévia do tempo das atividades existia, este não era cobrado pelas professoras. Ainda observaram que os relógios de ambas as salas, bem como de todas as outras salas da escola, com exceção dos relógios da sala dos professores e da cozinha, não funcionavam. Assim, concluíram:

As relações temporais que se estabelecem nestas salas de aula são marcadas pelo tempo vivido, relacionado somente com o presente e marcado por situações externas, como a hora da merenda. Não se encontra, na prática cotidiana, assim como no trabalho com a História, nenhuma proposta pedagógica que leve o aluno a trabalhar com antecipações sobre o que vai se fazer e em que tempo, o que seria uma ponte para a compreensão do tempo da intenção. Assim sendo, é explicável a dificuldade que muitos demonstram em trabalhar com linhas do tempo ou calendários. (ibidem, p.126)

Interessaram às autoras as formas pelas quais as crianças aprendem e se relacionam com o tempo, a partir das formas de organização do tempo escolar. Porém, ao atribuírem o controle do tempo às merendeiras, por intermédio do sinal para o lanche, e considerarem essa prática como uma situação 'externa', inviabilizaram uma análise sobre outras formas de compreensão temporal, diferentes daquelas relacionadas com a exclusividade do uso dos relógios ou marcadores oficiais do tempo.

Acreditamos que as relações temporais, obviamente, não podem dialogar apenas com as dimensões do tempo presente (como o tempo imediato da merenda), todavia devem também estabelecer relações com outras lógicas de organização do tempo, diferentes daquela compreensão instaurada pelas disciplinas de trabalho das sociedades modernas (Thomsom, 1998). Pensar o 
mundo historicamente é também pensá-lo sob outras lógicas de organização temporal, como a hora do lanche, e isso não nos parece ser um elemento exterior aos sujeitos da aprendizagem.

\section{Alguns Referenciais de TEMPo E ESPAÇO A SEREM CONSIDERADOS NA COMPREENSÃO DO CONHECIMENTO HISTÓRICO}

É justamente com o apoio de outras correntes historiográficas como a História social inglesa, a História das mentalidades e a História cultural que o ensino de História tem atuado de uma forma que supere, por exemplo, dimensões positivistas, levando à problematização e compreensão do processo histórico, permitindo que os estudantes se localizem historicamente no seu presente de forma a intervir na construção do seu futuro individual e social.

O conhecimento historiográfico sobre as temporalidades e espaços é essencial para a formação e visão do aluno sobre o processo histórico, principalmente numa perspectiva de Educação Histórica, tal como assinalaram Maria Auxiliadora Schmidt e Isabel Barca. ${ }^{7}$ Para superar a fragilidade da abordagem acerca do espaço-tempo, os docentes podem realizar atividades teórico-práticas que desenvolvam no aluno a curiosidade para fazer, vivenciar e construir o conhecimento. É sempre importante lembrar que o tempo, enquanto abstração teórica, só existe e pode ser significado em sua relação com algum referencial. O referencial principal, a ser considerado no ambiente escolar, deve ser sempre o aluno, seu tempo, seu espaço, seu contexto, isso antes de qualquer proposição didática sobre as noções pretendidas.

Práticas simples podem dar direcionamentos enriquecedores às aulas. Situar os alunos, por exemplo, em relação aos conteúdos que serão trabalhados auxilia na construção desses referenciais. Transformar séculos em gerações, ou um século em uma senhora centenária, leva os alunos a terem outras percepções sobre as distâncias que os separam de determinados acontecimentos, pois eles conhecem senhoras centenárias e saberão estabelecer relações de proximidade/distanciamento com os conteúdos estudados.

Outra iniciativa válida é perguntar aos estudantes onde eles acham que os seus ancestrais estavam, o que faziam e como reagiram a determinado acontecimento. Esse exercício de imaginação histórica contribui para que essa relação com o tempo dos alunos, vivo, possa direcionar-se sobre o tempo das 
gerações que lhes foram anteriores. Em igual medida, também é positivo estabelecer essa aproximação entre tempos e espaços com base em experiências individuais, em suas dimensões coletivas. Sujeitos como Mahommah Gardo Baquaqua, ${ }^{8}$ Chica da Silva, ${ }^{9}$ ou ainda Zumbi dos Palmares, ${ }^{10}$ na temática das trajetórias de populações negras na diáspora e suas vivências no contexto da escravização, são ótimos links para que sejam estabelecidas relações de aproximação.

Para isso, é importante, ainda que aparentemente démodé, situar os alunos numa linha do tempo, pois foram os usos inadequados que transformaram essa linha na grande vilã das salas de aulas, após as principais tentativas de incorporação no ensino básico das mudanças epistemológicas pelas quais passou a produção do conhecimento histórico no século XX. A retomada dessa alegoria metodológica, a linha do tempo, ainda pode auxiliar-nos, enquanto professores de História, a conectar os sujeitos às historicidades e temporalidades das trajetórias humanas. Isso evitaria, em alguma medida, que algumas incoerências temporais fossem geradas pelos maus usos e leituras da História Nova, em especial pelos riscos deterministas da História Temática, ou, como assinalou Jacques Le Goff (1983), “A História Nova em fatias é a pior das Histórias". ${ }^{11}$

Os riscos dessa falta de referenciais temporais podem ser percebidos por todos aqueles que trabalham no ensino básico, basta solicitar aos alunos que situem determinado acontecimento no seu respectivo século e, assim, saberão concretamente do que estamos falando. A falta de preocupação com datas/ marcos históricos não torna as aulas menos tradicionais, talvez um pouco mais confusas, mas a abolição desses referenciais em nada assegura que as abordagens dos conteúdos ocorram de modo problematizador. Sujeitos, Experiências, Cultura, Gênero, Cotidiano, Identidades, Representações, Práticas e Poder, todas estas demandas podem dialogar com os marcadores tradicionais do tempo.

A linha do tempo também pode ser utilizada e apreendida de outras formas. Pode ser flexível, tensionada, pode abranger movimentos dos mais diversos que nos auxiliem em sala de aula no processo de desnaturalização das atuais compreensões de tempo, fixas. Uma linha do tempo flexível contempla, representativamente, os processos de continuidades e descontinuidades que perpassam os fazeres históricos. 
A aprendizagem com mapas é essencial para o estudante de História no reconhecimento do espaço, o qual pode ser o seu entorno, a cidade, estado e/ ou país. Não raramente, os alunos associam as atividades com mapas às aulas de geografia. Essa aprendizagem deve respeitar dois aspectos básicos: o trabalho com o espaço de ação (vivenciado) mais próximo dos estudantes e a construção dos mapas pelos próprios sujeitos. Ao introduzir o trabalho de mapeamento de espaços de vivências do aluno, é importante que o professor tenha oportunizado ao menos uma ampla discussão e um grande número de experiências/atividades envolvendo não só a noção de espaço, mas também a necessidade de orientação (onde estamos, para onde nos deslocamos, qual o lugar que vou estudar).

O ensino de História deve ampliar, portanto, as possibilidades de utilização dos mapas, por entender que a História trabalha, fundamentalmente, com essas duas vertentes, tempo e espaço, bem como deve utilizar o tempo cronológico para situar o estudante na linha do tempo - mediante calendários e datas - sobre os fenômenos e fatos históricos, concomitantemente com um processo de ensino-aprendizagem que permita ao aluno identificar diferentes níveis e ritmos de durações temporais.

Os níveis das durações temporais dos acontecimentos históricos estão "relacionados à percepção das mudanças ou das permanências nas vivências humanas". ${ }^{12}$ Os ritmos de duração temporal permitem identificar a velocidade das mudanças ocorridas e podem ser entendidos como breves (quando a duração do fato corresponde apenas a um momento pontual, expresso por uma data, como nascimento ou morte de determinada pessoa histórica), conjunturais (fenômeno que se estende durante certo período e que marca a vida dos indivíduos desse tempo, como o período de uma guerra ou de uma crise econômica) e, por fim, estrutural (mudanças nas estruturas são imperceptíveis para a sociedade local no decorrer desse período de longa duração, como o período no qual vigora certa forma de organização familiar ou ainda um sistema de produção e de relação de trabalho) (MEC, 1997).

Esses ritmos temporais podem parecer difíceis ou inacessíveis aos nossos alunos do ensino básico, mas a demonstração de Fernand Braudel sobre o evento, por exemplo, traduz uma complexa compreensão de tempo numa simples metáfora que pode, sim, ser utilizada didaticamente como modo de perceber aspectos peculiares do tempo histórico: 
Guardei a lembrança, uma noite, perto da Bahia, de ter sido envolvido por um fogo de artifício de pirilampos fosforescentes; suas luzes pálidas reluziam, se extinguiam, brilhavam de novo, sem romper a noite com verdadeiras claridades. Assim são os acontecimentos: para além de seu clarão, a obscuridade permanece vitoriosa. (Braudel, 1992)

Assim, um acontecimento histórico, localizado no tempo e no espaço, pode ser compreendido pela análise integrada das diversas conjunturas que exercem influência sobre o fato, bem como do processo estrutural no qual este está inserido, examinando-o ao longo de uma temporalidade mais extensa. Essas dimensões temporais podem ser relacionadas às durações apreendidas por Braudel - curta, média e longa.

Ainda em relação ao olhar e olhares dos historiadores sobre os fatos históricos, Norbert Elias, em sua obra Sobre el Tiempo, sintetiza:

Como práctica ordinaria y profesionalmente aceptada, los historiadores aplican a grupos e individuos del pasado, todos los criterios posibles que sirvan para juzgar a los contemporáneos. No es nada raro encontrar historiadores que sientan en el banquillo de los acusados a hombres indefensos de otras épocas y los juzgan según sus valores del tiempo presente. Transmiten así la impresión de que entre la prehistoria y el presente no existiesen diferencias esenciales ni hubiesen ocurrido cambios en las fases de desarrollo anteriores. ${ }^{13}$

Para um ensino de História que considere os aspectos espaço-temporais como elementos de construção da compreensão de mundo, mister se faz dotar de sentido esse ensino, visto que é graças a ele que o aluno constrói uma visão global de uma sociedade complexa em permanente mudança no tempo, numa dimensão mais abrangente e plural do mundo. A relação recorrente que se pretende entre passado e presente, no ensino de História, não corresponde à construção de análises anacrônicas, pelo simples fato de tomarmos o imediato como referência, tal como assinalou Marco Silva. ${ }^{14}$ Tomemos os conceitos de democracia e cidadania - eles não permanecem na atualidade com acepções iguais às da Antiguidade Clássica. Quando tomamos o imediato como referência, estimulamos os alunos a desenvolverem percepções sobre as mudanças e, neste aspecto, não incorremos no risco do anacronismo, apenas estabelecemos relações significativas com as experiências do passado. 
Enfim, o ensino de História com base nestas considerações possibilita que

los alumnos comprendan que los hechos históricos, y su temporalidad son construcciones hechas por los historiadores y que estos mismos pueden ser construidos e interpretados de manera diferente por otros historiadores y por los ciudadanos. En consecuencia, la enseñanza de la historia supone implicarles en la aventura del saber y del saber hacer propio del trabajo historiográfico, y, en esta aventura, la construcción de la temporalidad es fundamental. ${ }^{15}$

Como fazer que os alunos compreendam esse tempo histórico como construção historiográfica, humana? Talvez os saberes e referenciais dos alunos possam nos fornecer algumas possibilidades para a realização dessa tarefa.

Aplicada uma avaliação escrita para uma turma de 9oano, em que uma das perguntas era "Como você percebe o tempo histórico em sua vida?", as principais referências de tempo para esses alunos estavam associadas às seguintes noções: mudanças, marcas, inovações, lembranças, passado, futuro, vida, gerações, crescimento, nascimento e envelhecimento. Compreensões que, embora reconheçam as relações entre passado/presente/futuro e, em alguma medida, apresentem a ideia de mudança, ainda estão associadas a um tempo muito recente, marcado pelas mudanças de gerações, nascimento, envelhecimento, quase que uma leitura naturalizada do tempo. Os aspectos da vida cotidiana dignos de serem 'lembrados' também constituem essa História apreendida pelos alunos. As percepções em longa e média duração, por exemplo, parecem ser pouco notadas.

O imediato como referência deve, sim, fazer parte das elaborações históricas, mas, associadas a ele, devem ser inseridas outras dimensões que constituem o tempo histórico. Nesse sentido, antes que essas dimensões temporais trazidas pelos alunos sejam descartadas, faz-se necessário construir, com base nesses referenciais, outras formas de perceber o tempo. Um aluno disse que o tempo histórico 'passa mesmo quando estou dormindo', ou seja, é um tempo que é exterior aos sujeitos, às suas ações e vontades.

Portanto, para além das abordagens de tempo com os recursos tradicionais, podem ocorrer discussões acerca dos marcadores do tempo, por exemplo (calendários, relógios, linhas do tempo). Já que o tempo histórico apontado por muitos não apresentava uma dimensão criada pelos homens, então podemos discutir esses referenciais trazidos pelos próprios. Para além das 
tradicionais referências de percepção/marcadores do tempo, não devemos ficar alheios a marcadores inusitados, como o espelho, citado por uma aluna como um dos marcadores do tempo - apenas ao olhar-se no espelho ela dizia perceber o tempo. Descartar essas referências não nos parece ser a atitude mais adequada, pois o entrecruzamento de referências possibilita a apreensão do tempo como construção humana.

É necessário que o tempo histórico seja considerado em toda sua complexidade, abarcando as vivências pessoais - pelas modificações temporais biológicas (nascimento, crescimento, envelhecimento) e psicológicas (mudanças internas) de cada um - bem como percebendo esse tempo como uma resultante da produção social das civilizações ao longo de diferentes lugares e momentos, ou seja, como um Objeto da cultura. É da cultura que nascem concepções de tempo tão diferenciadas como o tempo mítico, escatológico, cíclico ou cronológico, noções ${ }^{16}$ sociais criadas pelo homem para representar as temporalidades naturais, expressas nos tempos geológico e astronômico. ${ }^{17}$

\section{Novas APREENSÕES TEMPORAIS INSTAURADAS PELAS NTIC}

Em nossa sociedade, nos dias de hoje, o tempo é um tempo de ritmo acelerado, tempo das descobertas científicas, da relação capital-trabalho-produção, de cada sociedade que dá o compasso do cotidiano, estabelecendo-se por vários meios: percepção, reflexão e maneira pessoal de sentir e viver. Os seres humanos devem ser levados a perceberem que o passado está presente na sua vida atual, visto que as experiências acumuladas, somadas às transformações biológicas, psicológicas e sociais por que passam, resultam no que são e no que vivem no presente.

Nesse caso, não se considera que a vida pregressa está separada do momento atual e do futuro; a pessoa tem a clara percepção de que tudo o que ela é no presente é fruto do já vivenciado: seus conhecimentos adquiridos na primeira infância, sua aprendizagem no seio familiar, os estudos na escola, as brincadeiras, as competições nos esportes, o ingresso no mundo do trabalho, a formação de sua própria unidade familiar, tudo está integrado e resulta na sua capacidade de perceber o mundo e na sua forma de projetar o futuro. Assim, no plano individual não há separações formais entre o passado, o presente e o futuro. 
Acerca da relação entre passado, presente e futuro, Joan Pagès diz que:

Los hechos y los fenómenos sociales tienen sus raíces en el pasado y se proyectan ineludiblemente hacia el futuro. Por eso el presente constituye una franja temporal muy débil, muy etérea, de límites imprecisos, que necesita del pasado para concretarse, pues éste es el único que ya ha sido. Sin embargo, el pasado sin el presente carecería de valor ya que la explicación que de éste da aquél es el resultado, es el fruto, de los problemas y de los interrogantes que el hombre tiene sobre su propio tiempo y sobre el futuro. Es esta relación dialéctica entre el pasado, el presente y el futuro lo que da sentido a la temporalidad dialéctica. (Pagès, 2004)

Em consequência disso, os docentes têm se deparado com uma realidade desafiadora no que diz respeito ao contexto das aulas do ensino básico, pois os estudantes lidam cotidianamente com novas linguagens e novas percepções de espaço e tempo advindas das tecnologias que alteram a sua percepção das próprias categorias. Em vez de utilizarmos essas novas percepções em sala de aula, associadas às nossas práticas de ensino de História, temos nos limitado à inserção de novas linguagens, como a fílmica e a iconográfica, mas pouco dialogamos com essas outras dimensões de tempo e espaço.

Muitas vezes as novas tecnologias são utilizadas apenas como recursos e quase nunca problematizadas como um fenômeno que modifica as próprias noções de tempo e espaço dos alunos. Uma ótima alternativa seria fazer uso dessa destituição dimensional, de espaço e tempo, que a virtualidade condiciona e à qual os alunos estão familiarizados, para estabelecermos links entre o tempo presente dos alunos e os acontecimentos no tempo passado. As possibilidades de trânsito entre espaços e o alargamento das noções de tempo, marcadas pelo fato de irmos de um espaço a outro sem que seja preciso sair de casa, e em tempo real, são terreno fértil para sugerirmos aos nossos alunos passeios por outras temporalidades.

Essas outras percepções de espaço, tempo e linguagens, advindas das tecnologias, impõem uma nova realidade que se apresenta, segundo Vani Moreira Kenski, em dois aspectos:

O primeiro diz respeito aos procedimentos realizados pelo grupo de alunos e professores no próprio espaço físico da sala de aula. Neste ambiente, a possibilidade de acesso a outros locais de aprendizagem - bibliotecas, museus, centro de pesquisas, 
outras escolas etc. com os quais alunos e professores podem interagir e aprender - modifica toda a dinâmica das relações de ensino-aprendizagem. Em um segundo aspecto, é o próprio espaço físico da sala de aula que também se altera. ${ }^{18}$

Embora a escola atual permaneça em descompasso com as rápidas mudanças sentidas na sociedade, é certo que as NTIC vêm influenciando o processo de ensino-aprendizagem. O professor, embora atento a essas mudanças, ainda não modificou epistemologicamente a sua prática, apenas tem alterado metodologicamente as aulas. Exibições de vídeos, documentários, filmes ou iconografias, com direcionamentos que reproduzem os mesmos questionamentos das tradicionais aulas de História, o conteúdo pelo conteúdo, não estimulam nos alunos o interesse pelo conhecimento histórico.

Para integrar as NTIC no mundo escolar é necessário que o professor tenha conhecimento das suas potencialidades com base na ação e nas práticas educativas. Em vez de partir de um esquema 'preestabelecido' para aplicar à 'realidade posta', procura-se relacionar a teoria e a prática a partir da implicação dos sujeitos no ambiente educacional. Uma possibilidade dessa articulação tem sido a elaboração de Objetos Digitais de Aprendizagem, ${ }^{19}$ em formatos que, quando bem concebidos, inserem dimensões interacionistas aos conteúdos históricos lecionados em salas de aula. Esses Objetos são ótimos exemplos de mudanças metodológicas acompanhadas de mudanças epistemológicas no ensino de história, pois alteram o tipo de relação que é estabelecida entre os conteúdos e os sujeitos do conhecimento. No que se refere ao estudo baseado em Objetos de Aprendizagem e sua importância para o estudante, Paixão (2012, p.7) diz que:

Na construção do conhecimento os objetos de aprendizagem têm como diferencial uma nova forma de comunicar o conteúdo, provocando o estudante para se debruçar sobre a pesquisa. Nesse processo, o estudante elabora outras formas de apropriação desse conhecimento. ${ }^{20}$

Nesse sentido, um aspecto importante advindo da relação entre tecnologias e ensino de História refere-se às novas compreensões de espaço e tempo que o mundo tecnológico instaura. A dimensão espaço-temporal se modifica no espaço virtual, trazendo para o ensino de História o entendimento do que se dá no entorno dos sujeitos. Segundo Eduardo José Reinato, 
No cyberespaço o espaço é destituído de dimensão. Primeiramente, não é considerado um espaço físico, ele é virtual ... O tempo por sua vez em relação ao espaço toma uma outra dimensão ... superpõe-se ao espaço. O tempo real em que transito no cyberespaço, ainda que o faça de forma virtual, é marcado pelo fato de que vou de um espaço ao outro sem sair da frente do meu computador ... em tempo real e sem sair de casa. Assim, o cyberespaço acaba por construir um mundo espacial paralelo. ${ }^{21}$

Sabemos que é quase impossível relacionarmo-nos com as percepções temporais nas sociedades modernas sem que, para isso, o diálogo com as tecnologias seja estabelecido. O relógio é uma dessas tecnologias, mas não a única. Sabemos que as NTIC têm possibilitado, continuadamente, que cada indivíduo possa construir e alterar a sua identidade pertencendo a vários grupos ao mesmo tempo - aqui temos a ampliação dos referenciais de tempo/espaço. Novos laços de comunidade criam-se com as NTIC. Mas o real e o imaginário misturam-se, pois existe um novo modo de ver, sentir, pilotar e organizar a realidade. Nesse novo mundo, a pessoa entra em contato e partilha, mas permanece 'no seu mundo', não se preocupa em construir uma comunidade local.

A sociedade em que hoje vivemos exige, cada vez mais, o uso das tecnologias, mas estas, por seu lado, modificam a própria cultura criada pelo homem. A aprendizagem carece de interação social e as NTIC permitem um maior acesso à informação, possibilitando o reforço das relações entre sujeitos no espaço e no tempo.

\section{Algumas COnsiderações finais}

Para o mundo educativo, e o ensino de História em particular, também se faz necessário perceber e entender a importância do tempo. O tempo representa, assim como o espaço, um aspecto essencial para a construção e compreensão do processo histórico, tanto no seu aspecto social quanto no individual. $\mathrm{O}$ ensino de História tem papel preponderante no estabelecimento das conexões entre os tempos (passado e presente), para que os estudantes possam formar o conceito de temporalidade e, assim, compreender a dimensão histórica da realidade. 
Além disso, o tema 'espaço e tempo' - ao fazer parte do contexto da escola - não deveria estar apenas nos conteúdos trabalhados pelos professores, mas integrado ao currículo escolar. Nesse sentido, a concepção de educação histórica permite que a escola esteja atenta às epistemologias que permeiam os currículos. Currículo e escola devem situar elementos que sejam propiciadores da construção de referenciais espaço-temporais na sua própria lógica de organização dos conteúdos e da dinâmica do cotidiano escolar. Porém, sabemos que, apesar de essas escolas se encontrarem inseridas numa sociedade da informação, as primeiras ainda permanecem organizadas segundo uma lógica que compreende os níveis de ensino, a seriação e as avaliações aplicadas progressivamente, e imprimem uma compreensão de tempo linear, evolutiva e teleológica ao conduzir quase naturalmente a um só tempo, o futuro. Nas atuais configurações curriculares e organizacionais das escolas, como é possível a construção de habilidades/competências cognitivas que insiram outras lógicas de tempo e espaço?

Essa integração curricular das percepções de tempo e espaço é apontada por Joan Pagès:

la temporalidad debería formar parte de los objetivos de la enseñanza de las ciencias sociales y en particular de la historia. Sin embargo, parece bastante evidente que ello no es así en bastantes de los curricula al uso. Al contrario, lo más frecuente es que la temporalidad se adquiera de forma espontánea e intuitiva, al margen de la escuela. (Pagès, 1998)

A construção dos conceitos de tempo e espaço pelos estudantes torna-se fácil à medida que eles elaboram o próprio conhecimento, visto que, no decorrer desse processo, concretizam e sistematizam noções construídas espontaneamente, podendo, posteriormente, abstraí-las.

Nesse sentido, o professor de História se apresenta como elemento que constrói a relação com o conhecimento histórico, podendo propiciar ao aluno o estabelecimento dos referenciais fundamentais em que assenta essa tomada de consciência do tempo social, estimulando-o a construir o saber histórico pela expressão de 'opiniões históricas' na sua linguagem, desde os primeiros anos de escolaridade. Essa construção do pensamento histórico é progressiva e gradualmente contextualizada, em função das experiências vividas dentro e fora da escola. Assim, o aluno estará apto a: 


\section{Temporalidade:}

- Localizar acontecimentos da História pessoal e familiar, e da História local e nacional; reconhecer e utilizar, no cotidiano, unidades de referência temporal;

- Aplicar os conceitos de mudança/permanência na caracterização das sociedades que se constituíram no espaço brasileiro em diferentes períodos; identificar, localizar no tempo e caracterizar alterações significativas da sociedade brasileira;

- Identificar e caracterizar as principais fases do processo histórico e os grandes momentos de ruptura deste mesmo processo;

- Desenvolver a noção de multiplicidade temporal; distinguir ritmos de processo em sociedades diferentes e no interior de uma mesma sociedade; estabelecer relações entre passado e presente;

- Explicitar as dinâmicas temporais que impulsionam as sociedades humanas, notadamente as permanências, transformações, desenvolvimentos, crises, rupturas e revoluções e as contribuições para o mundo contemporâneo.

\section{Espacialidade:}

- Resolver situações que envolvam deslocamentos, localizações, distâncias e, por associação e comparação, situar-se relativamente a espaços mais longínquos, relacionando-os pelo estabelecimento de ligações de várias ordens;

- Conhecer a localização relativa ao território brasileiro, caracterizando os principais contrastes na distribuição espacial das atividades econômicas e formas de organização em diferentes períodos, relacionando-as com fatores físicos e humanos;

- Localizar e situar no espaço as diversas formas de representação espacial, os diferentes aspectos das sociedades humanas e seus processos, notadamente a expansão de áreas habitadas e os fluxos demográficos, a organização do espaço urbano e arquitetônico, as áreas de intervenção 
econômica, o espaço de dominação política e militar e o espaço de expansão cultural e linguística.

Para os fins propostos, procuramos valorizar a utilização pertinente do conhecimento de acordo com as necessidades e as situações que se apresentem nos processos de sala de aula e/ou fora deles, tornando-se fundamental a organização do ensino-aprendizagem em bases claras e bem definidas, sustentadas em situações de aprendizagem específicas que possam construir nos educandos mapas conceituais que os ajudem a pensar e a usar o conhecimento histórico de forma criteriosa e adequada. ${ }^{22}$

O estudo do espaço e do tempo na educação básica pode propiciar aos educandos aprendizagens de escuta, observação e investigação, fundamentais para o desenvolvimento cognitivo, crítico e criativo. E, ao promover a união entre a teoria e a prática, o educador ou educadora poderá fazer das suas atividades propostas experiências reais e significativas para cada aluno. Por isso, os conteúdos e atividades devem partir, também, das próprias experimentações, pensamentos e sensações dos educandos.

Levá-los a trabalhar noções de espaço e tempo despertando um olhar sobre as ideias de diferenças, semelhanças, continuidades e permanências é um estímulo à curiosidade, à criação de hipóteses, a questionamentos, à elaboração de estratégias para entender e explicar os acontecimentos históricos e culturais que lhes são apresentados, tornando-se, com base em sua experienciação, sujeitos reflexivos e autônomos. ${ }^{23}$

\section{NOTAS}

${ }^{1}$ A historiografia já direcionou muitas discussões sobre o tempo histórico. Além de F. Braudel e E. P. Thompson, citados, ver Reinhart Koselleck, George Duby e Paul Ricoeur.

${ }^{2}$ BRAUDEL, Fernand. Escritos sobre a História. São Paulo: Perspectiva, 1992.

${ }^{3}$ THOMPSON, E. P. Costumes em comum: estudos sobre a cultura popular tradicional. São Paulo: Companhia das Letras, 1998.

${ }^{4}$ CARBÓ, Maria Jesús Comellas. Las habilidades básicas de aprendizaje: análisis e intervención. 2.ed. Barcelona: EUB, 1996.

${ }^{5}$ PAGÈS, Joan; BENEJAM, Pilar (Coord.). Enseñar y aprender ciencias sociales, geografía e historia en la educación secundaria. 2.ed. Barcelona: ICE; Horsori Ed., 1998.

${ }^{6}$ ZAMBONI, Ernesta; OLIVEIRA, Sandra Regina Ferreira de. O espaço e o tempo no pro- 
cesso de ensinar e aprender História na sala de aula. História Revista, Revista da Faculdade de História e do Programa de Pós-Graduação em História, Universidade Federal de Goiás, v.14, n.1, 2009. p.118.

${ }^{7}$ SCHMIDT, Maria Auxiliadora; BARCA, Isabel. Aprender História: perspectivas da educação histórica. Ijuí (RS): Unijuí, 2009.

${ }^{8}$ Em relato autobiográfico Mahommah Gardo Baquaqua registra suas experiências na condição escrava e seu itinerário pelas Américas, em que encontramos elementos singulares da memória como suas identificações étnico-religiosas, suas estratégias pela conquista da liberdade e suas vivências na condição de homem livre, além do acentuado vínculo preservado com a África. Parte de sua autobiografia, a que se refere ao período em que Baquaqua esteve no Brasil, pode ser encontrada na Revista Brasileira de História: LARA, Silva Hunold (Org.). Biografia de Mahommah G. Baquaqua. RBH, São Paulo: Anpuh; Marco Zero, v.8, n.16, mar.-ago. 1988.

${ }^{9} \mathrm{O}$ estudo de Furtado sobre Chica da Silva nos ajuda a desconstruir algumas imagens instituídas pela memória coletiva e que de algum modo diferem da história de vida dos reais sujeitos. FURTADO, Junia. Chica da Silva e o contratador dos diamantes: o outro lado do mito. São Paulo: Companhia das Letras, 2003.

${ }^{10}$ Sobre a trajetória de Zumbi dos Palmares é importante ver: GOMES, Flávio dos Santos. Zumbi dos Palmares: histórias, símbolos e memória social. São Paulo: Claro Enigma, 2011. (Coleção De olho em).

${ }^{11}$ Jacques Le Goff (1983), citado por MUNAKATA, Kazumi. Histórias que os livros didáticos contam depois que acabou a ditadura no Brasil. In: FREITAS, Marcos Cezar de (Org.). Historiografia brasileira em perspectiva. São Paulo: Contexto, 2005.

12 BRASIL. Ministério da Educação. Secretaria de Educação Fundamental. Parâmetros Curriculares Nacionais: ensino médio: história e geografia. v.5. Brasília, 1997.

${ }^{13}$ ELIAS, Norbert. Sobre el tempo. 2.ed. Mexico: FCE, 1997.

${ }^{14}$ SILVA, Marcos A. da. História: o prazer em ensino e pesquisa. São Paulo: Brasiliense, 1995. p.23.

${ }^{15}$ PAGÈS, Joan; BENEJAM, Pilar (Coord.). Enseñar y aprender ciencias sociales, geografía e historia en la educación secundaria. 4.ed. Barcelona: ICE; Horsori Ed., 2004.

${ }^{16}$ PAGĖ, Joan. Aproximación a un currículo sobre el tiempo histórico. In: RODRÍGUEZ F. J. (Ed.). Enseñar historia: nuevas propuestas. Barcelona: Laia; Cuadernos de Pedagogía, 1998.

${ }^{17}$ BRASIL. Ministério da Educação. Secretaria de Educação Média e Tecnológica. Parâmetros Curriculares Nacionais: ensino médio: ciências humanas e suas tecnologias. v.4. Brasília, 1999.

${ }^{18}$ KENSKI, Vani Moreira. Novas tecnologias: o redimensionamento do espaço e do tempo e os impactos no trabalho docente. Revista Brasileira de Educação, São Paulo: Associação Nacional de Pós Graduação e Pesquisa em Educação, n.8, maio-ago. 1998. 
${ }^{19}$ A esse respeito ver o excelente trabalho de Eremita Tânia Silva da Paixão em: www.iat. educacao.ba.gov.br/objetoseducacionais. Acesso em: 7 set. 2012; tecnologia.iat.educacao. ba.gov.br/banco_de_objetos?title=\&type=All\&term_node_tid_depth $=42 \&$ autor $=\&$ tid_1 = All; Acesso em: 7 set. 2012.

${ }^{20}$ PAIXÃO, Eremita Tânia Silva da. Produção de objetos de aprendizagem para aulas de História: entre teoria e prática. In: ENCONTRO DA ASSOCIAÇÃO NACIONAL DE HISTÓRIA, 6. Ilhéus (BA), ago. 2012. Anais...

${ }^{21}$ REINATO, Eduardo José. Informática e educação: primeiras viagens pela internet: exemplificando uma experiência e uma inquietação de pesquisa. Disponível em: www.ceveh.com.br/biblioteca/artigos/index.htm; Acesso em: 10 ago. 2012.

${ }^{22}$ Adaptação do Projeto Curricular de Escola. Disponível em: pages.madinfo.pt/eb1pemachico/PROJECTO\%20CURRICULAR\%20DE\%20ESCOLA.pdf.

${ }^{23}$ FERREIRA, Carlos Augusto Lima. La Formación y la práctica de los profesores de Historia: enfoque innovador, cambios de actitudes e incorporación de las nuevas tecnologías en las escuelas públicas y privadas de la provincia de Bahía, Brasil. Tese (Doutorado) - Departamento de Pedagogía Aplicada. Barcelona, 2003.

Artigo recebido em 15 de julho de 2012. Aprovado em 12 de setembro de 2012. 